\title{
Sulfacetamide Sodium
}

National Cancer Institute

\section{Source}

National Cancer Institute. Sulfacetamide Sodium. NCI Thesaurus. Code C29467.

The sodium salt form of sulfacetamide, a synthetic sulfanylacetamide derivative with bacteriostatic activity. Sulfacetamide inhibits bacterial folic acid synthesis by competing with para amino benzoic acid. With a broad spectrum of action, it is used as an antiinfective topical agent to treat skin infections and as an oral agent for urinary tract infections. ( $\mathrm{NCl04)}$ 